Fostering Students' Collaborative Learning Competencies and Professional Conduct in the Context of Two Gross Anatomy Courses in Veterinary Medicine

\title{
Laakkonen, Juha
}

2019

Laakkonen , J \& Muukkonen , H 2019 , ' Fostering Students' Collaborative Learning Competencies and Professional Conduct in the Context of Two Gross Anatomy Courses in Veterinary Medicine ' , Anatomical Sciences Education , vol. 12 , no. 2 , pp. 154-163 . https://doi.org/10.1002/ase.18

http://hdl.handle.net/10138/325160

https://doi.org/10.1002/ase.1811

acceptedVersion

Downloaded from Helda, University of Helsinki institutional repository.

This is an electronic reprint of the original article.

This reprint may differ from the original in pagination and typographic detail.

Please cite the original version. 
ASE-17-0230.R1

Research Report

\title{
Fostering students' collaborative learning competencies and professional conduct in the context of two gross anatomy courses in veterinary medicine
}

\author{
Juha Laakkonen ${ }^{1}$, Hanni Muukkonen ${ }^{2}$ \\ ${ }^{1}$ Department of Veterinary Biosciences, Faculty of Veterinary Medicine, University of Helsinki, \\ Finland \\ ${ }^{2}$ Faculty of Education, University of Oulu, Finland
}

Running title: Collaborative learning and professional conduct in anatomy

Correspondence to: Dr. Juha Laakkonen, Department of Veterinary Biosciences, Faculty of Veterinary Medicine, B.O. Box 66, 00014 University of Helsinki, Finland. E-mail:

juha.laakkonen@helsinki.fi

Grant sponsor: The European Commission Grant KNORK

Grant number: 402765 543154-LLP-1-2013-1-FI-KA3-KA (HM)

Grant sponsor: Academy of Finland Grant

Grant number: ARONI 285806 (HM) 


\begin{abstract}
Collaborative learning has been used in anatomy courses to support students' learning of challenging topics but the success of group work depends significantly on the students' ability to communicate in a professional manner. Veterinary students' experiences with tasks related to collaborative learning and professional conduct were studied by comparing learning collaborative competences and pedagogy, as well as perceived positive and challenging aspects, in two gross anatomy courses. Both qualitative and quantitative data was collected from students' experiences of course assignments and collaboration, as well as from self-evaluated collaboration competence development. Trying things out oneself, practical application and professional conduct were positively highlighted particularly in the first-year course (myology and arthrology) group work and learning from others more in the second year (topographical anatomy). Various group work challenges, often relating to practical matters or communication, were the key concerns for students. The main difference between the two courses in learning of collaborative knowledge work competencies appeared to relate to the nature of the group work assignment. The topography course included the element of collaboration in preparing a presentation and teaching session for the rest of the class. Interestingly, students on the myology and arthrology course gave more positive comments on professional conduct than the students on the topography course despite the fact that the latter course included more practical elements relating to their future profession.
\end{abstract}

Keywords: gross anatomy education, veterinary medical education, undergraduate education, collaborative learning, collaboration, professional conduct 


\section{INTRODUCTION}

Students often find gross anatomy difficult because it includes a great deal of terminology, which may hinder the ability of the student to see the animal as an anatomical entity. This translates into an instructional design challenge to foster students' disposition for deep understanding of the regional anatomical entities (Terrell, 2006; Ward and Walker, 2008; McCune and Entwistle, 2011) rather than supporting practices which encourage fast intake of large amounts of superficial details. Collaborative learning and peer teaching has been used in many ways in various disciplines to support students' learning of challenging topics (Nnodim, 1997; Brueckner and MacPherson, 2004; Youdas et al., 2008), including anatomy (Thurman et al., 2009; Khosa et al., 2010; Salomäki et al., 2014). However, the success of group work and peer teaching depends significantly on students' ability to effectively communicate and collaborate (Allen and Boraks, 1978; Evans and Cuffe, 2009; Muukkonen and Lakkala, 2009).

This study focused particularly on how two courses in the preclinical phase of studies in gross anatomy were designed and experienced by students. The challenge in both courses was to specify instructional design choices in dissection exercises to foster an understanding of regional anatomical entities, professional conduct, and learning collaborative knowledge work competences. We studied the learning aims of these two courses in relation to the strategies that exist in teaching professionalism (Branch et al., 2001; Mueller, 2009), taking into consideration that there are differences in communication between human and veterinary medical education. The role of the companion or production animal owner brings an additional dimension to the communication in veterinary medicine. In all medical sciences, however, education in communication should aim for flexible skills so that the student learns to communicate with 
various health professionals using professional terms as well as with patients or owners using layman's terms.

\section{Professionalism begins with proper professional conduct}

The parameters describing the term professionalism have changed over time (van Mook et al., 2009), and within professional society (Mueller, 2009) and culture (Roder et al., 2012; Cruess and Cruess, 2016), but include such topics as communication, collaboration and leadership skills, an ability for life-long learning and research utilizing various knowledge resources, as well as an ability to adapt to various working environments (Escobar-Poni and Poni, 2006; Bok et al., 2011; Mossop, 2012). Across disciplines there has also been a call to ensure that students learn generic competencies including critical and analytical thinking (e.g., Strijbos et al., 2015) as well as knowledge work competencies that describe utilization of collective efforts facing open-ended problems, the rich use of modern technologies, encounters with real-world complexity through work life contacts and developing specific tasks for some relevant use (Lakkala et al., 2015). In addition to communication skills, other non-technical professional competencies, such as empathy and self-efficacy, have also been supported by evidence to be important elements of professionalism (Mueller, 2009; Cake et al., 2016).

The importance of emphasizing professionalism even in the earliest years of undergraduate medical education, including in gross anatomy courses, has been pointed out in many studies (Escobar-Poni and Poni, 2006; Lachman and Pawlina, 2006; Pawlina, 2006; Camp et al., 2010). The terms professionalism or professional skills which include many of the same skills included here were not used in this study because these skills also include many clinical first day skills and other skills such as business (Mossop and Cobb, 2013), which are relevant for 
the clinical stage of veterinary education. Since this was the first time professional conduct was given as a learning objective in our anatomy curriculum, and since it differed from the anatomical learning objectives, the definition of this objective was discussed with the students during the first lecture of the course.

The Faculty of Veterinary Medicine at the University of Helsinki adheres to the operating procedures of the European Association of Establishments for Veterinary Education (EAEVE, 2016). In veterinary education the minimum standard required and the starting point for a variety of roles in the veterinary profession is known as "One Day Competences". The EAEVE procedures include several Day One Competences relevant for this study: "the ability to communicate effectively with clients, the public, professional colleagues, and responsible authorities, using language appropriate to the audience concerned," "to work effectively as a member of a multidisciplinary team in the delivery of services," "be able to review and evaluate literature and presentations critically," and "demonstrate that they recognize personal and professional limits, and know how to seek professional advice, assistance and support when necessary" (EAEVE, 2016).

Since both courses examined in this study were preclinical courses, the framework for learning professional conduct concentrated on the skills already needed in the beginning of medical studies. First, students should learn to use proper anatomical and medical terms from the very beginning of their studies as well as be able to communicate in all matters concerning the learning in dissection exercises. Secondly, students should recognize the need to respect and share the cadavers so that all students have equal opportunities for learning. Thirdly, the dramatic increase in the use of social media by students (Coe et al., 2011, 2012; Cartledge et al., 2013; Kedrowicz et al., 2016) has also created a need to discuss and agree on the proper way that 
dissection work is discussed in the social media without compromising the rights of cadaver donors. This is related to unprofessional practices like unauthorized dissection hall photography (Karunakaran et al., 2017).

Cadaver dissection forms the backbone for learning gross anatomy The challenge of initial dissection courses is to construct daily learning outcomes and evaluations that assess student understanding and integration of content (Burns, 2010) but do not consist of entities too large to properly understand, given the limited anatomical knowledge students have at this early stage of their education. It is also important to recognize that a professional, authentic approach to cadavers may be overwhelming for some students not used to unpleasant sights, smells and emotions related to cadaver dissection.

Cake (2006) has suggested that many traditional anatomy practices, such as dissection, are compatible with active, student-centered learning strategies and the adoption of deep learning. In the University of Helsinki, the veterinary anatomy curriculum is designed to encourage personal student engagement by limiting the number of lectures to allow for three dissection courses (lasting two to three weeks) which cover the systematic anatomy in dogs, cats, horses and cows during the first year. Each course builds on knowledge learned during the previous courses. The second year ends with a dissection course on topographical anatomy with the focus on anatomical entities and practical applications, which introduce a new context for professional conduct. The topographical course is designed to challenge the communication skills of students (Branch et al., 2001; Mueller, 2009) by introducing a new learning method, peer teaching. It is important to effectively align the instructional design of successive dissection courses so that students can draw on prior understanding to make learning personally meaningful (Terrell, 2006; 
Ward and Watson, 2008) and to promote understanding of gross anatomical entities. The teaching of reflective skills and the use of early clinical experience to provide valid learning opportunities are likely to be good motivational methods also for first dissection course, especially since they also relate to professionalism (Mossop and Cobb, 2013).

\section{Collaboration competences}

The benefits of collaborative learning have been well documented in a variety of disciplines (Gokhale, 1995; Zimbardo et al., 2003; Michael, 2006; Green et al., 2016) including anatomy curricula (Dunkin and Hook, 1978; Vasan et al., 2011; Durán et al., 2012; Kamei et al., 2012; Hall et al., 2013; Huitt et al., 2015). The key benefits have been identified as involvement in active learning (Michael, 2006), students taking responsibility for their own learning (Vasan et al., 2011), efficiency in terms of faculty to student ratios (Durán et al., 2012), improved student results (Vasan et al., 2011) and peer-peer learning, although findings are not universal (Green et al., 2016). Besides learning theory and hands-on skills, group work and peer teaching with cadavers provides opportunities to learn communication, collaboration and leadership right from the start of medical education (Pawlina et al., 2006). Professionalism builds on this ability to understand and integrate disciplinary knowledge with practical expertise, trained decision making and communication. A previous study (Salomäki et al., 2014) showed that veterinary students at the University of Helsinki experience difficulties in expressing their concerns openly and in seeking guidance. This demonstrated the need to improve students' communication skills. Feedback comments from the students indicated that the collaborative learning method in anatomy dissection courses not only deepens student understanding of the subject matter but also offers an opportunity to practice generic skills (Salomäki et al., 2014). 


\section{Aim of the study}

The usefulness of collaborative learning in anatomy dissection courses was analyzed by comparing two gross anatomy courses which differed in instructional design and the level of regional anatomical understanding required. The aim of this study was to gain information on the student perspective on learning anatomy in different dissection courses, but also to challenge and test the instructional designs for the very first and last dissection courses in the veterinary anatomy curriculum of the University of Helsinki. In the cadaver laboratory context at the Faculty of Veterinary Medicine, University of Helsinki, group work assignments and collaborative learning are the methods of choice for practical reasons (shortage of cadavers, time or teachers) but also because it resembles a real-world situation in which veterinary professionals must work as a team with a patient (in this case a cadaver). Cadaver laboratory dissection teachers are thus in a good position for promoting professionalism (Escobar-Poni and Poni, 2006) and to serve as role models passing on professional attitudes and behaviors (Pawlina, 2006).

The Finnish veterinary degree program consists of a six-year science-based education carried out at the University of Helsinki. No other university in Finland has a veterinary faculty. First-year veterinary students form a heterogeneous group consisting of recent school graduates as well as older students with previously completed university studies and even degrees. Along with cell biology, biochemistry and histology, courses on the anatomy of companion and production animals are among the first courses in the veterinary curriculum at the University of Helsinki. After osteology, myology and arthrology is the first gross anatomy course. The secondyear students study genetics, microbiology, pathology and parasitology before ending the term 
with the topographical anatomy course. Many of the challenges students face at the beginning of their studies are similar to those in other veterinary faculties (Laakkonen and Nevgi, 2014, 2017) but there are differences in students' approaches to learning compared to other universities (Laakkonen and Nevgi 2017; Ruohoniemi et al., 2017). Compared to students at the University of Bologna, for example, Finnish students scored significantly lower in the deep approach to learning, organized studying and constructive feedback (Ruohoniemi et al., 2017). This clearly relates to the themes of this study, such as communication and understanding of anatomical entities.

This study draws on theoretical development in the learning sciences to measure collaborative knowledge work competencies. There is an emphasis on the role of artifacts and objects in mediating advanced practices in sense making and interaction (Paavola and Hakkarainen, 2005; Säljö, 2010). Students' activities in learning are designed (1) through interaction around shared knowledge objects, here the gross anatomy of studied species, and professional conduct at the dissection exercise with various tools, artefacts and digital resources, and (2) the phasing of the study activities of individual studying, group work dissection exercises, group assessment and formative feedback. The study aims to document the effects of design choices by describing the pedagogical design details, asking students about their experiences of the courses and by student assessment of their competence development in knowledge work. The specific research questions were: (1) How did the students evaluate the courses' positive and challenging aspects?; (2) Did the two examined courses differ in how collaborative knowledge work competencies were learned?

\section{MATERIALS AND METHODS}




\section{Context of the study}

The general faculty feedback (Appendix A) and the description of instructional design was used as a starting point for the comparison of the two courses examined in this study. Furthermore, students were asked to respond to a questionnaire on learning knowledge work practices, the Collaborative Knowledge Practices Questionnaire (Muukkonen et al., 2017), which was completed at the end of each course. Student experiences and practices concerning the two courses were examined in detail based on how the students evaluated what was challenging or difficult and positive or impressive about each course.

\section{Ethical approval}

Ethical issues were carefully considered and the ethical rules of the university were followed. The evaluative feedback data were routinely collected by the Faculty. At induction, students were informed that, during their studies, feedback would be collected regularly and anonymously to improve the quality of their and future students' learning and that this and additional coursespecific feedback might be used for future research publications. This type of low-risk evaluation study is exempt from separate approval from the ethics committee at the University of Helsinki. Besides an oral introduction to the purpose of the study given at the beginning of each course, instructions for filling the CKP questionnaire were provided by a separate e-mail. Participation was voluntary and students' responses were anonymous.

The two gross anatomy courses examined here consisted of lectures, palpation and dissection exercises. The dissection exercises were carried out in groups of five to six students (with a total of 34-36 students in the dissection laboratory at the same time). All dissection laboratory periods have detailed learning objectives (see below) available to students in lecture notes and/or dissections instructions. 


\section{Myology and arthrology course}

The three-week myology and arthrology course consisted of lectures ( 8 hours), and dissection exercises mainly on cats, but also on some specimens of dogs, horses and bovines (48 hours including palpation exercises with live animals). It is the second gross anatomy course (after osteology) in the curriculum of first-year students. For practical reasons, the students were divided into two dissection groups (morning and afternoon groups). No concurrent courses were run at the same time, allowing students to have half a day of study time to reflect on their learning and prepare for the next day's work. Two to three teachers supervised and helped the students during the dissection work.

The learning objectives of the course were: (1) to locate and identify the principal muscles of the body by dissection (teachers provided a list of the dissected muscles along with basic information about these muscles, e.g., origin, insertion, function); (2) to determine how the function of the muscles differs in various domestic species by comparing the size and attachment points in different species; (3) to identify the principal joints and their structural components by dissection; (4) to learn to work and behave as part of a professional group, share responsibilities to complete the learning tasks and communicate using proper anatomical terms (defined as professional conduct for the purpose of this preclinical anatomy dissection course).

At the end of each exercise, each dissection group consisting of five or six students had to demonstrate to teachers that they had found all the muscles and joint structures that formed the particular exercise. If this oral examination was passed, the student obtained one point towards the final course assessment, which included a written test at the end of the course. A maximum of seven points could be gained from the oral examinations and used towards the final grade (a 
total of 30 points). In order to pass, students needed to gain 50 percent of the maximum points. At the end of the course, feedback on professional conduct was provided to the dissection groups by the teachers. Professional conduct was not scored in the written examination in any way.

\section{Topographical anatomy course}

The twelve-day topographical anatomy course consisted of lectures (4 hours), dissection exercises (33 hours), as well as group work and study time without teachers (44 hours). No concurrent courses were run at the same time. This course completed the second study-year at the end of May.

The learning objectives of the course were: (1) to perceive the topographical location of gross anatomical structures within different parts of the body; (2) to perceive the projection of major organs into the outer surface of the animal, and how this information can be used in clinical work; (3) to understand the stratigraphy of the body; (4) to repeat some of the gross anatomy knowledge gained in the systematic anatomy courses; (5) to acquire professional conduct as defined for the muscles course (see above).

During the first day of the course, each group was asked to design and perform an approach to a specific cat or dog limb joint, and to record all the gross anatomical structures they encountered. The aim of the exercise was to repeat information from the basic anatomy courses of their first study year. During the second day, each group was given instructions for a surgical approach to the same joint the group had dissected the day before. After completing the task, groups demonstrated the approach to other groups (they were approaches for five different joints). Each group also had a week to complete a written dissection report in which they compared their own anatomical approach to the surgical one, and reflected on differences in the 
anatomical structures encountered, tissue damage and reasons for the differences in the two approaches. The aim of these two exercises was to guide students to reflect on the relevance of anatomical knowledge in future clinical work, and to encourage critical thinking about the course content.

During the second week of the topographical anatomy course, each group had to prepare an oral presentation of a particular topographical entity (head, limbs or pelvis) of horses, bovines and/or dogs, using skeletons, (plastinated) cadaveric material, diagnostic imaging figures and whatever material the students could think of to visualize or otherwise demonstrate the topographical entities to the teachers and other students. The exercise also included practical information, for example which structures can be palpated, or where to insert a needle when blocking a nerve.

During the third week of the topographical anatomy course, each group prepared for an oral examination (held by the teachers) of the thorax and abdomen of horses, bovines and dogs/cats. Again, students were able to use skeletons, cadaveric and other material as well as written guidelines produced by teachers for this course to prepare for the oral examination. The aims of the second- and third-week exercises were for the students to gain understanding of anatomical and topographical entities, and how this information is used in clinical work as well as encourage peer-peer learning. During the topography course teachers closely supervised the entire dissection work and peer-peer teaching but only helped if students were unable to solve a problem, actively asked for help, or there were factual errors in their peer-to-peer teaching. No written examination was included in the course.

On both courses, students had access to the anatomy textbooks in the dissection hall and to the learning sources in the internet (each group had a tablet) during the dissection work. 


\section{Participants and data collection}

The data included feedback collected by the faculty after each course and responses to the Collaborative Knowledge Practices (CKP) questionnaire (Muukkonen et al., 2017). The faculty feedback consisted of an electronic questionnaire, which included both open-ended questions and a statement that was rated using a five-point Likert scale. In this statement, students were asked to grade the overall design, content and execution of the course from poor (1) to excellent (5). The open-ended questions were as follows:

- Was there enough time to complete the dissection exercises?

- Mention factors that improved/hindered your learning

- How would you improve the course?

faculty feedback is part of the curriculum and all students must complete the questionnaire as part of the course. Thus, $100 \%$ of the students who registered for the courses (see below) completed the questionnaire.

The feedback responses and CKP questionnaire data were collected in autumn 2015 during a myology and arthrology course (in short muscles) among a class of first-year students (64 females, 5 males), 37 of whom participated in the study (54\% of the students registered for the course), and in spring 2016 during a topographical anatomy course (in short Topography) among a class of second-year students (63 females, 7 males), 20 of whom participated in the study (29\% of the students registered for the course). The mean age of participants was 22.8 years $(\mathrm{SD} \pm 5.62)$ in Muscles and $24.7(\mathrm{SD} \pm 4.39)$ in Topography.

A link to the CKP questionnaire was sent by the teacher to the class. Students gave informed consent and responded to the 27 items on a five-point Likert scale: "I learned during the 
course..." e.g., "to define sub-goals for the collaborative work" or "to comment on the work of others" "not at all" (1) - "very much" (5) (see Appendix B for the questionnaire). They also answered two open-ended questions: What was challenging or positive about the course?

\section{Data analysis}

Qualitative content analysis on open-ended responses was carried out as a data grounded analysis process (Braun and Clark, 2006; Timmermans and Tavory, 2012). First, the data was read many times through and initial themes were noted. The data were then segmented into units of analysis addressing one idea, each unit of analysis first being given an initial coding based on the main theme it represented. The themes were then grouped into categories relating to students' experiences of the courses: Understanding and interest, Learning details, Group work and learning from others, Regulation and learning with others, Teaching methods and practices, and Doing things for oneself, Practical application, and Professional conduct. An alternative analysis method would have been to focus only on the key learning outcomes of our study (anatomy and professional conduct), but the choice was made to include all the themes offered by the students on the positive and challenging aspects of these courses. All the data were analyzed using the seven categories to examine the positive and challenging aspects but reported by maintaining knowledge of the type of input it provided (positive or challenging). The internal consistency of each category was examined by looking only at the units of analysis within one category, and amendments being made if necessary. The final categorization resulted in seven mutually exclusive categories (presented in results in detail). To analyze the inter-rater agreement of classification, an independent rater classified approximately $45 \%$ of the units of analysis; the 
Kappa coefficient for rater agreement was 0.713 (Cohen's Kappa) which was considered good congruity between raters (0.40-0.75 rated as fair to good, see Fleiss et al., 1969).

The responses of the CKP questionnaire were analyzed by SPSS statistical package, version 24 (IBM Corp., Armonk, NY). Scale items and reliabilities (Cronbach's alpha) are presented in Supplementary Material Appendix B; Cronbach's alpha reliability coefficient ranged between 0.71-0.79 indicating an acceptable internal consistency for each scale. A t-test was carried out to compare mean scores and effect sizes on the CKP questionnaire scales between the two courses.

\section{RESULTS}

\section{Overview of faculty feedback}

Based on the faculty feedback, students found the learning objectives of the muscle course clear and enjoyed the dissection work, where they can learn "hands-on" experience. They also feel that they learn better because the exercises have been broken down into smaller tasks. Negative feedback came mainly from the occasional lack of optimal dissection material, which consists mainly of donated specimens (for teaching and research). A few students also lamented the fact that some students learn very slowly, and thus slow down the group work and increase the time spent in the dissection exercises. Many students also stated in the course feedback that they gained confidence as they noticed that they were able to consistently pass the daily oral examination. Overall, students graded the muscle course excellent (76\%), good (22\%) or satisfactory (2\%). In the faculty feedback on the topography course, students stated that learning in groups and teaching to others was more beneficial than the assessment of the course content by a written test. Some students felt that better time management by teachers would have helped the learning process (e.g. students had too much freedom to choose when to present their 
findings). Overall, students graded the topography course excellent (51\%), good (46\%) or satisfactory $(3 \%)$.

\section{Students' comments on the positive and challenging aspects of courses}

Data-grounded analysis of the open responses highlighted seven categories of experiences, which varied between the courses (see Table 1). The Muscles course highlighted particularly enthusiasm based on the practical and hands-on nature of the course, challenges with learning details, and regulation of collaboration. The Topography course raised more positive aspects about understanding the learning content, group work and learning from others, but also difficulties in collaboration. Both the negative and positive aspects of the teaching methods were commented on.

\section{Understanding and interest}

Students related the challenges of understanding to the activities and knowledge entities they were asked to address during the dissection sessions. It appeared that the students valued being able to examine the studied topics directly in the cadaver materials, as well as holding discussions while trying to gain an understanding of the overall task. However, sometimes the three-hour sessions were felt to be tiring because one had to stay focused for a long time. Most challenging was maybe the intensity of dissection work. In a short timeframe we went through a large number of muscles and one needed to be able to [orally] do an exam at the end of each session directly based on the group's cadaver material. (Muscles)

\section{Learning details}


Students commented on being faced with a considerable number of new terms during the course, and they were worried if they could handle it all in such a short time (three weeks). The reading material for one course was considered particularly complicated. What the students also wondered what kind of approach to take to learning the materials. During the course it has been challenging to differentiate between essential and additional knowledge. Should one learn all the million specific terms or mainly the large and clinically important structures. (Topography)

\section{Group work and learning from others}

In the comments, group work was addressed from two points of view. The first was named group work and learning from others, because the comments brought up both positive and challenging aspects about the epistemic aspects of learning together. Students wrote about how working together influenced their learning.

Noticing the benefits of working in a group: learning out loud together, and by repeating things could be taken in very well. It was also fun to notice how the other groups presented their work and progress without being asked to when you went to see how they were working: at the same time one learned from other groups' work topics. (Topography)

\section{Regulation and learning with others}

Another dimension of group work related to the regulation and co-regulation of collaboration and how learning with others was experienced. Students pointed out that it can be tiresome both to collaborate all the time and to adjust one's activities to the group objectives and pace of working. Working in a group has its own challenges and it is at times surprisingly hard. (Muscles) Some of dimensions were initially considered challenging but the group approved 
them later during the course. It was during the first entire week challenging to identify the group's shared practices, but once we identified them, working together was very rewarding and educational. (Topography)

\section{Teaching methods and practices}

One category of responses related to the selected teaching methods and practices during course work. Students commented that they found the group work, the various types of materials, the teacher being available for questions, and completing the exercises with verbal demonstration very valuable. At the end of the exercise, we needed to demonstrate what we had learned to the teachers; that's why one needed to concentrate properly on each exercise and learning was maximal. (Muscles)

However, sometimes the freedom offered to groups was seen as too much and larger groups posed a challenge for equal distribution in activities. In a group it's not always possible to get an equal share of cutting the cadaver and in larger groups it's hard to see the small anatomical structures when someone's head is always in the way. (Topography)

\section{Doing oneself, practical application, and professional conduct}

One aspect emphasized by the pedagogical design of the course was to teach professional conduct, expert practices, and decision making. Particularly the first-year students considered the chance to work with real animal material very significant. We got to do things ourselves and look at real muscles in real animals. It would have been much harder to learn only from pictures. (Muscles) 


\section{Some features of working with dissection materials remained hard to cope with.}

The smell of the cadavers was at times hard to bear (Muscles). However, students very often mentioned that practical exercises on the course were very important.

\section{Competences related to collaborative knowledge work}

Finally, this study addressed how students reported having learned competences related to collaborative knowledge work. The main difference between the two courses in learning collaborative knowledge work competences appeared to relate to the nature of the group work assignment. The above analysis of the open comments pointed out that in the Topography course students wrote more comments about collaboration compared to the Muscles course. This suggested to us that the learning about collaboration was more prominent in that course. The results of the CKP questionnaire (Figure 1) provided supporting evidence as the students from the Topography course gave statistically significantly higher scores on the scales of learning concerning collaboration on shared objects $(\mathrm{M}=3.89, \mathrm{SD} \pm 0.63)(\mathrm{t}(52)=-4.00, P<0.001, d=$ $1.13)$ and integrating individual and collaborative working $(4.15, \mathrm{SD} \pm 0.61)(\mathrm{t}(52)=-2.22, P<$ $0.05, d=0.62)$ compared to the Muscles course $(\mathrm{M}=3.16, \mathrm{SD} \pm 0.65)$ and $(\mathrm{M}=3.77, \mathrm{SD} \pm 0.60)$, respectively. A marked difference in two the courses concerned how collaboration was pedagogically designed: in the Muscles course, students intensively discussed, studied, and worked collaboratively around the dissection table. In the Topographical anatomy course they had, in addition, to prepare a teaching session to the whole class about a selected topic, e.g., "The head as an anatomical entity" or "The topographical anatomy of limbs." It appears that this shared object, the teaching presentation or demonstration, intensified the need to collaborate and learn the related competences on planning, coordinating and sharing responsibility during 
collaboration as well as the integration of individual and collaborative phases and contributions while working. As with the other scales, there were no significant differences between the courses $(P>0.05)$, effects sizes (Cohen's $d$ ) between 0.08 and 0.28 , other than the learning to exploit technology which had the medium effect size of 0.48 . Scores on persistent development of knowledge objects were higher, while understanding various disciplines and practices, interdisciplinary collaboration, and learning to exploit technology were not targeted in the courses and had lower scores.

\section{DISCUSSION}

Analysis of the Myology and arthrology and Topographical anatomy courses showed that the students evaluated the courses' positive and challenging aspects in multiple ways (Table 1): more positive than negative aspects were raised. Doing things for oneself, practical application and professional conduct were highlighted particularly in the first-year course, group work and learning from others more in the second year.

Interestingly, students on the Muscles course gave more positive comments on the professional conduct and practical application than the students on the topography course, despite the fact that the latter course includes more practical elements relating to their future profession. This could be due to the discussion held with the students on the importance of professional conduct in the beginning of the Muscles course, but also to the novelty of dissecting cadavers. As previous studies showed (Laakkonen and Nevgi 2014; 2017), students become more stressed as they advance in their preclinical studies, partly because after the initial excitement of the first dissection course they begin to realize how well they need to master the preclinical topics (such as anatomy and physiology) before starting their clinical studies. Such 
anxiety may shift attention from professional conduct to the individual needs of students trying to secure all the necessary information before entering the clinical studies. This warrants further studies and the need to teach and assess professional conduct and attitudes, as well as changes in such conduct and attitudes (Pearson and Hoagland, 2010) throughout the curricula (Pawlina et al., 2006; Rees and Knight, 2007; Wittich et al., 2013).

In this study, progress in professional conduct was not assessed in the written examination of the Muscles course but it was discussed with the dissection groups at the end of both courses. It has been previously reported that students appreciate the opportunity to discuss professionalism issues related to the dissection of cadavers (Spampinato et al., 2014). As teacher and peer feedback is widely recognized to be an important mechanism for development, progress in professional conduct needs to be assessed in a structured way in the future. The main difference between the two courses in the learning of collaborative knowledge work competencies appeared to relate to the nature of the group work assignment. The Topography course included the element of collaboration to prepare a presentation and teaching session for the rest of the class, which advanced competences emphasized by the CKP scales on collaboration on a shared object and integration of individual and collective efforts. By the end of the second study year, students also knew each other much better than during the very first dissection course, which may make working together easier for students. From the perspective of the entire veterinary education curriculum, it would be valuable to examine whether those collaborative knowledge work competencies not targeted by the anatomy curriculum, namely understanding various disciplines, interdisciplinary collaboration and exploiting technology, will be learned during later studies. 
Proper dissection work requires many hours of concentrated work, which may be difficult for some young students used to the fast-paced virtual world. Also, during the Myology and arthrology course (the first dissection course), students are still getting used to the new learning environment with its occasionally unpleasant sights, smells and emotions, which may well slow down the dissection work. Thus, some veterinary students may not feel academically prepared for their first-year courses (Sutton, 2007), while other, more experienced students, are eager to get the hands-on experience provided by the dissection opportunity (Laakkonen and Nevgi, 2014). This creates a challenge for the learning of collaboration competencies during the first dissection course.

\section{Implications and further directions for the instructional design and assessment practices of}

\section{the courses}

First-year course.

The heterogeneity of the first-year students (consisting of recent secondary school graduates as well as older students with previously completed university studies and even degrees) created differences between students in the way they value the evaluation (by oral examination) of learning tasks. As a teacher, it appeared that some of the less experienced students see the oral assessments as stressful occasions for memorizing facts, while the more experienced students often see them as a way to learn about smaller anatomical entities before the final written examination covering the entire muscle system. Similarly, Ward and Walker (2008) showed that memorization had the greatest variability in the academic achievement of first-year veterinary students, which may imply that memorization works well for some students and poorly for others. 
The teachers emphasize, prior to and during the Muscle course, the value of daily studying of anatomical entities, for example the anatomical structures involved in the extension and flexion of the elbow joint. However, some students seem to spend much of the dissection time in learning the necessary anatomical terms (instead of familiarizing themselves with at least some of them in advance), leading to superficial learning and failure to learn anatomical entities. An effort was made to address these challenges by providing various written instructions for the dissection periods, but only starting in 2016 were all written instructions of consecutive dissection courses similar in form to provide instructive alignment between different dissection periods.

\section{Second-year course.}

Verbal presentation and "flag-race" or similar style assessments have been suggested to be forms of assessment that require greater understanding of spatial relationships (Clough and Lehr, 1996) compared to written examinations. Partly because of this, oral examinations and peer teaching replaced the written examination in the topographical anatomy course which, of all the anatomical courses, requires the deepest understanding of spatial relationships. An additional challenge seems to be how to address the feeling of some students that they learn and understand slightly different entities. Also, some groups have decided by themselves to do additional work and complete also the dissection tasks relating to the topographical entities presented orally by the other groups, thus gaining a better understanding of the various topographical entities.

Similar to the results of a previous study (Green et al., 2016), it was observed that collaborative oral examinations do not always create a successful culture of peer-peer learning 
amongst all students. This may be partly due to the fact that some students are unprepared when they come to the dissection exercises, thus creating heterogeneous learning groups where peerpeer learning is one-sided. This challenges teachers to create dissection tasks which encourage all students to be prepared and eager to participate. Reciprocal peer teaching has been used to increase the level of preparedness prior to the dissection course but not all students feel comfortable about teaching (Krych et al., 2005; Salomäki et al., 2014).

The development of brief oral examinations of the muscle course into collaborative practical tests (Green et al., 2016) of larger anatomical entities, and topographical group work into team-based learning (Vasan et al., 2011) warrants further research. Free-riding appears to be a minor problem in the preset study partly due to the relatively large groups (five to six students). Student group size is determined by the size of the learning environment, cadaver material and the number of teachers available for the course.

The anxiety related to the need to learn everything that a veterinarian is required to do is very strong throughout veterinary education. Similarly, despite being instructed to focus only on the most relevant terms, many students try to learn everything and see anything lower than the top grade as failure. Therefore, students have very high expectations for themselves and the challenge appears to be to teach them to focus on the most beneficial features of collaboration, monitoring the understanding of entities rather than embracing each detail, as well as raising awareness of professional critical thinking and decision making throughout the courses. In addition, more pronounced explication of the benefits of collaborative learning is needed by encouraging students to share their findings and ideas not just within their own dissection group but also with other groups, even when it is not given as a learning goal or task in the syllabus. 
This kind of conduct also ties collaborative learning more closely to the concept of professional conduct.

\section{Limitations of the study and future research}

The data examined consisted of student feedback from two courses, which provided a perspective on students' views on the positive and challenging aspects of the courses. The inclusion of learning outcomes measured from both courses as well as measures for assessing professional conduct and students' reflections on it would have provided a more complete dataset for addressing the learning gains in relation to instructional design. More data combining subject-level learning outcomes from various courses is needed to explicate in detail the relationship of the pedagogical practices and students' dynamic understanding of gross anatomy, learning of professional conduct, and knowledge work competences.

Future studies need to address how in educational settings to overcome the lack of structured feedback on professionalism from peers (Tucker et al., 2017). A previous study on first-year medical students suggests that feedback on professionalism is best presented on an individual basis to improve professional behavior (Camp et al., 2010), while another study (Tucker et al., 2017) points out the importance of observing a role model providing feedback on professionalism. Therefore, there should be detailed studies on whether feedback to first-year students should be provided in a different way from the more experienced students in the clinical phase of their studies. Small-group role play has been shown to be an effective way to foster professionalism in a clinical setting (Baillie et al., 2010), and could be a useful method to teach professional conduct in a safe, relatively stress-free environment also for students in the preclinical phase of their veterinary studies. 


\section{CONCLUSIONS}

Although understanding of anatomical entities is challenging, it should be an important learning aim of all courses on gross anatomy because in the future profession of veterinary students, an animal is most often encountered as a living entity. Learning collaboration competencies was supported by collaboration assignments that besides interacting and discussing around the dissection exercise also demanded preparing and presenting a shared knowledge object (a teaching session) in class. If learning knowledge work competencies and professional conduct are specifically included as learning aims of all anatomy courses, this may help students to see the cadaver as a kind of patient requiring a holistic approach from a group of professionals. 


\section{ACKNOWLEDGEMENTS}

The authors wish to thank the students who participated in this study. This work was in part supported by the European Commission under Grant KNORK

402765 543154-LLP-1-2013-1-FI-KA3-KA (HM) and the Academy of Finland Grant ARONI $285806(\mathrm{HM})$. 


\section{NOTES ON CONTRIBUTORS}

JUHA LAAKKONEN, Ph.D., is a university lecturer in the Department of Veterinary

Biosciences at the Faculty of Veterinary Medicine, University of Helsinki, Finland. He teaches gross anatomy of domestic and wildlife animals mainly to first-, second-, and third-year veterinary medical students. His pedagogical research interests are in the area of collaborative learning and well-being of students in educational transitions.

HANNI MUUKKONEN, Ph.D., is a professor in educational psychology at the Faculty of Education, University of Oulu, Finland. She carries out research on collaborative learning, knowledge creation, teacher training, and technology in education. 


\section{LITERATURE CITED}

Allen AR, Boraks N. 1978. Peer tutoring: Putting it to the test. Read Teach 32:274-278.

Baillie S, Pierce SE, May SA 2010. Fostering integrated learning and clinical professionalism using contextualized simulation in a small-group role-play. J Vet Med Educ 37:248-253.

Bok GJ, Jaarsma DA, Teunissen PW, van der Vleuten CPM, van Beukelen P. 2011. Development and validation of a competency framework for veterinarians. J Vet Med Educ 38:262-269.

Branch WT Jr, Kern D., Haidet P, Weissmann P, Gracey CF, Mitchell G, Inui T. 2001. The patient--physician relationship. Teaching the human dimensions of care in clinical settings. JAMA 286:1067-1074.

Braun V, Clarke, V 2006. Using thematic analysis in psychology. Qual Res Psychol 3:77-101.

Brueckner JK, MacPherson BR. 2004. Benefits from peer-teaching in the dental gross anatomy laboratory. Eur J Dent Educ 8:72-77.

Burns ER. 2010. "Anatomizing" reversed: Use of examination questions that foster use of higher order learning skills by students. Anat Sci Educ 3:330-334. 
Cake MA. 2006. Deep dissection: Motivating students beyond rote learning in veterinary anatomy. J Vet Med Educ 33:266-271.

Cake MA, Bell MA, Williams JC, Brown FJ, Dozier M, Rhind SM, Baillie S. 2016. Which professional (non-technical) competencies are most important to the success of graduate veterinarians? A Best Evidence Medical Education (BEME) systematic review: BEME Guide No. 38. Med Teach 38:550-563.

Camp CL, Gregory JK, Lachman N, Chen LP, Juskewitch JE, Pawlina W. 2010. Comparative efficacy of group and individual feedback in gross anatomy for promoting medical student professionalism. Anat Sci Educ 3:64-72.

Cartledge P, Miller M, Phillips B. 2013. The use of social-networking sites in medical education. Med Teach 35:847-857.

Clough RW, Lehr RP. 1996. Testing knowledge of human gross anatomy in medical school: An applied contextual-learning theory method. Clin Anat 9:263-268.

Coe JB, Weijs CA, Muise A, Christofides E, Desmarais S. 2011. Teaching veterinary professionalism in the Face(book) of change. J Vet Med Educ 38:353-359. 
Coe, JB, Weijs CA, Muise A, Christofides E, Desmarais S. 2012. Understanding veterinary students' use of and attitudes toward the social networking site, Facebook, to assist in developing curricula to address online professionalism. J Vet Med Educ 39:297-303.

Cruess SR, Cruess RL. 2016. Professionalism as a social construct: The evolution of a concept. J Grad Med Educ 8:265-267.

Dunkin E, Hook P. 1978. An investigation into the efficiency of peer teaching. Assess Eval High Educ 4:22-45.

Durán CE, Bahena EN, Rodríguez Mde L, Baca GJ, Uresti AS, Elizondo-Omaña RE, López SG. 2012. Near-peer teaching in an anatomy course with a low-faculty-to-student ratio. Anat Sci Educ 5:171-176.

Escobar-Poni B, Poni ES. 2006. The role of gross anatomy in promoting professionalism: A neglected opportunity! Clin Anat 19:461-467.

EAEVE. 2016. European Association of Establishments for Veterinary Education. European System of Evaluation of Veterinary Training (ESEVT): Manual of Standard Operating Procedure. 2016 Ed. Wien, Austria: European Association of Establishments for Veterinary Education. 108 p. URL: https://www.eaeve.org/fileadmin/downloads/SOP/ESEVT_Uppsala_SOP_May_2016_amende 
d_Annex_8__13_Rubrics_approved_by_ExCom_on_25Jan2017.pdf (accessed 15 March 2018).

Evans DJ, Cuffe T. 2009. Near-peer teaching in anatomy: An approach for deeper learning. Anat Sci Educ 2:227-233.

Fleiss JL, Cohen J, Everitt BS. 1969. Large sample standard errors of kappa and weighted kappa. Psychol Bull 72:323-327.

Gokhale AA. 1995. Collaborative learning enhances critical thinking. J Tech Educ 7:22-30.

Green RA, Cates T, White L, Farchione D. 2016. Do collaborative practical tests encourage student-centered active learning of gross anatomy? Anat Sci Educ 9:231-237.

Hall ER, Davis RC, Weller R, Powney S, Williams SB. 2013. Doing dissections differently: A structured, peer-assisted learning approach to maximizing learning in dissections. Anat Sci Educ 6:56-66.

Huitt TW, Killins A, Brooks WS. 2015. Team-based learning in the gross anatomy laboratory improves academic performance and students' attitudes toward teamwork. Anat Sci Educ 8:95103.

Kamei RK, Cook S, Puthucheary J, Starmer CF. 2012. 21 ${ }^{\text {st }}$ century learning in medicine: 
Traditional teaching versus team-based learning. Med Sci Educ 22:57-64.

Karunakaran I, Thirumalaikolundusubramian P, Nalinakumari DS. 2017. A preliminary survey of professionalism teaching practices in anatomy education among Indian medical colleges. Anat Sci Educ 10:433-443.

Kedrowicz AA, Royal K, Flammer K. 2016. Social media and impression management: Veterinary medicine students' and faculty members' attitudes toward the acceptability of social media posts. J Adv Med Educ Prof 4:155-162.

Khosa DK, Volet SE, Bolton JR. 2010. An instructional intervention to encourage effective deep collaborative learning in undergraduate veterinary studnets. J Vet Med Educ 37:369-376.

Krych AJ, March CN, Bryan RE, Peake BJ, Pawlina W, Carmichael SW. 2005. Reciprocal peer teaching: Students teaching students in the gross anatomy laboratory. 18:296-301.

Laakkonen J, Nevgi A. 2014. Relationships between learning strategies, stress, and study success among first-year veterinary students during an educational transition phase. J Vet Med Educ 41:284-293.

Laakkonen J, Nevgi A. 2017. Veterinary students' experience of stress during educational transition phases and its effect on self-regulation. In: Kyndt E, Donche V, Trigwell K, 
Lindblom-Ylänne S (Editors). Higher Education Transitions: Theory and Research. $1^{\text {st }}$ Ed. Abingdon, Oxon, UK: Routledge. p 155-171.

Lachman N, Pawlina W. 2006. Integrating professionalism in early medical education. The theory and application of reflective practice in the anatomy curriculum. Clin Anat 19:456-460.

Lakkala M, Toom A, Ilomäki L, Muukkonen H. 2015. Re-designing university courses to support collaborative knowledge creation practices. Austral J Educ Tech 31:521-536.

McCune V, Entwistle N. 2011. Cultivating the disposition to understand in $21^{\text {st }}$ century educations. Learn Indiv Differ 21:303-310.

Michael J. 2006. Where's the evidence that active learning works? Adv Physiol Educ 30:159167.

Mossop LH. 2012. Is it time to define veterinary professionalism? J Vet Med Educ 39:93-100.

Mossop LH, Cobb K. 2013. Teaching and assessing veterinary professionalism. J Vet Med Educ 40:223-232.

Mueller PS. 2009. Incorporating professionalism into medical education: The Mayo Clinic experience. Keio J Med 58:133-143. 
Muukkonen H, Lakkala M, Toom A, Ilomäki L. 2017. Assessment of competences in knowledge work and object-bound collaboration during higher education courses. In: Kyndt E, Donche V, Trigwell K, Lindblom-Ylänne S (Editors). Higher Education Transitions: Theory and Research. $1^{\text {st }}$ Ed. Abingdon, Oxon, UK: Routledge. p 288-305.

Nnodim JO. 1997. A controlled trial of peer-teaching in practical gross anatomy. Clin Anat $10: 112-117$.

Pawlina W. 2006. Professionalism and anatomy: How do these two terms define our role? Clin Anat 19:391-392.

Pawlina W, Hromanik MJ, Milanese TR, Dierkhising R, Viggiano TR, Carmichael SW. 2006. Leadership and professionalism curriculum in the gross anatomy course. Ann Acad Med Singapore 35:609-614.

Pearson WG Jr, Hoagland TM. 2010. Measuring change in professionalism attitudes during the gross anatomy course. Anat Sci Educ 3:12-16.

Rees CE, Knight LV. 2007. The trouble with assessing students' professionalism: Theoretical insights from sociocognitive psychology. Acad Med 82:46-50.

Roder C, Whittlestone K, May SA. 2012. Views of professionalism: A veterinary institutional perspective. Vet Rec 171:595. 
Ruohoniemi M, Forni M, Mikkonen J, Parpala A. 2017. Enhancing quality with a research-based student feedback instrument: A comparison of veterinary students' learning experiences in two culturally different European universities. Qual High Educ 23:249-263.

Salomäki T, Laakkonen J, Ruohoniemi M. 2014. Students as teachers in an anatomy dissection course. J Vet Med Educ 41:60-67.

Spampinato CM, Wittich CM, Beckman TJ, Cha SS, Pawlina W. 2014. "Safe Harbor": Evaluation of a professionalism case discussion intervention for the gross anatomy course. Anat Sci Educ 7:191-198.

Strijbos J, Engels N, Struyven K. 2015. Criteria and standards of generic competences at bachelor degree level: A review study. Educ Res Rev 14:18-32.

Sutton RC. 2007. Veterinary students and their reported academic and personal experiences during the first year of veterinary school. J Vet Med Educ 34:645-651.

Terrell M. 2006. Anatomy of learning: Instructional design principles for the anatomical sciences. Anat Rec 289B:252-260.

Thurman J, Volet SE, Bolton JR. 2009. Collaborative, case-based learning: How do students actually learn from each other? J Vet Med Educ 36:297-304. 
Timmermans S, Tavory I. 2012. Theory construction in qualitative research: From grounded theory to abductive analysis. Socio Theor 30:167-186.

Tucker C, Choby B, Moore A, Parker RS 2nd, Zambetti BR, Naids S, Scott J, Loome J, Gaffney S, Cianciolo AT, Hoffman LA, Kohn JR, O'Sullivan PS, Trowbridge RL. 2017. Teachers as learners: Developing professionalism feedback skills via observed structured teaching encounters. Teach Learn Med 29:373-377.

van Mook WN, de Grave WS, Wass V, O'Sullivan H, Zwaveling JH, Schuwirth LW, van der Vleuten CP. 2009. Professionalism: Evolution of the concept. Eur J Intern Med 20:e81-e84.

Vasan NS, DeFouw DO, Compton S. 2011.Team-based learning in anatomy: An efficient, effective, and economical strategy. Anat Sci Educ 4:333-339.

Ward PJ, Walker JJ. 2008. The influence of study methods and knowledge processing on academic success and long-term recall of anatomy learning by first-year veterinary students. Anat Sci Educ 1:68-74.

Wittich CM, Pawlina W, Drake RL, Szostek JH, Reed DA, Lachman N, McBride JM, Mandrekar JN, Beckman TJ. 2013. Validation of a method for measuring medical students' critical reflections on professionalism in gross anatomy. Anat Sci Educ 6:232-238. 
Zimbardo PG, Butler LD, Wolfe VA. 2003. Cooperative college examinations: More gain, less pain when students share information. J Exp Educ 71:101-125.

Youdas JW, Hoffarth BL, Kohlwey SR, Kramer CM, Petro JL. 2008. Peer teaching among physical therapy students during human gross anatomy: Perceptions of peer teachers and students. Ana Sci Edu 1:199-206. 